\title{
Concurrent optimization of harvesting and road network layouts under steep terrain
}

\author{
Leo Gallus Bont • Hans Rudolf Heinimann • \\ Richard L. Church
}

Published online: 29 December 2012

(C) Springer Science+Business Media New York 2012

\begin{abstract}
Timber extraction is based on two transportation modes - off-road and on-roadthat are connected by a set of landing nodes. Forest operations planning that is oriented toward harvesting consists of concurrently locating a truck road network, designating landing/loading sites along that network, and allocating stands to specific harvest technologies (e.g., cable roads). In central Europe, this problem has, until recently, been solved primarily with rules of thumb. By contrast, only a few attempts, designed for plantation systems, have been made to find the mathematical optima. Here, we present a modeling approach to identify a minimal-cost solution for this problem of laying out truck roads and cable roads when the terrain is steep. This technique is based on a Mixed Integer Linear Programming formulation. Our approach is as good as or better than state-of-the-art methods. Here, the overall costs of harvesting and roading were decreased by about $7 \%$ compared with techniques that called for a heuristic solution only. Depending upon parameter choices, we also determined that a computing time ranging from $4 \mathrm{~min}$ to $8 \mathrm{hrs}$ was required when assessing a logging area of $4.3 \mathrm{~km}^{2}$.
\end{abstract}

Keywords Cable-yarding $\cdot$ Forest road network $\cdot$ Mixed integer linear programming problem $\cdot$ Steep terrain

L.G. Bont $(\bowtie)$

Institute of Terrestrial Ecosystems, ETH Zürich, Universitaetstrasse 16, CHN K 75.1, 8092 Zurich, Switzerland

e-mail: leo.bont@env.ethz.ch

H.R. Heinimann

Institute of Terrestrial Ecosystems, ETH Zürich, Universitaetstrasse 16, CHN K 72.2, 8092 Zurich, Switzerland

e-mail: hans.heinimann@env.ethz.ch

R.L. Church

Department of Geography, University of California, Santa Barbara, Santa Barbara, CA 93106-4060, USA

e-mail: church@geog.ucsb.edu 


\section{Introduction}

Transportation of materials both on- and off-road is the backbone of harvesting operations over gentle as well as steep terrain. Therefore, the costs of constructing those roads and covering transportation expenses are crucial factors when determining economic efficiency. The overall goal in planning is to find that combination of transportation and infrastructure components that minimizes their total cost. Matthews and Donald (1942) were the first to use geometric models of transportation networks to identify optimal design criteria such as road-spacings or densities. Heinimann (1998) expanded upon this approach to address network layout problems on slopes, locating the most suitable switching point between ground-based and cable-based harvesting concepts under geographically challenging conditions. [Here, "cable-based transport line" = "cable road".] A second stream of research was triggered by the introduction of digital elevation models (DEMs) on GIS systems. This enabled harvesting engineers to position spatially explicit, optimal, or at least near-optimal, road network layouts mathematically (Chung et al. 2004, 2008; Epstein et al. 2006).

However, even the best available techniques have significant shortcomings.

First, such methods focus on a sequence of clearcut-harvesting activities within a project area, while assuming no other silvicultural interventions will occur during a stand's life cycle. In contrast, forests in regions such as the Alps (the focus of our research) must be managed for a mix of goods and services. This requires a different harvesting regime of single- and group-selection activities that necessitate certain design traits:

(1) Cable roads running parallel to each other must emanate from numerous small landings rather than follow a pattern of cable roads that radiate from a few, huge landings. Therefore, cable machinery for the former can be installed almost anywhere along a forest road.

(2) Forest roads must be of high quality and built for long-term durability, which means that their construction is more expensive.

(3) Because the entire forest must always be accessible, a road network cannot be supplemented incrementally and road projects cannot be divided into several stages of installation.

Second, although currently available methods might simplify the problem of spatial variability in road construction costs, this may lead to sub-optimal solutions or road locations that entail severe construction problems.

Finally, state-of-the-art methods that tackle such problems can incorporate numerous aspects that make a model very complex. Therefore, their solutions are commonly, if not exclusively, achieved heuristically. Although good, feasible solutions can be obtained, an optimal or near-optimal solution is not guaranteed. It is also difficult, if not impossible, to determine the gap between a heuristic solution and optimality.

The study project presented here addressed those challenges, aiming to (1) develop a model for identifying an optimal road network that concurrently minimized the costs of road construction and on-/off-road transportation; and (2) compare that model with a stateof-the-art, greedy heuristics method (Epstein et al. 2006) in an effort to demonstrate the benefits of our new approach. Two different harvesting systems were considered: yarding with cable roads (off-road component) and access roads versus helicopter-logging, which is practiced in areas that cannot be reached economically by road and cable-yarder. For each alternative, we stipulated that all timber parcels must be harvested.

As part of our project outline, we first reviewed the computer-aided techniques that are currently utilized for laying out a spatially explicit forest road network. We then proposed 
a modeling formulation that could be solved to optimality. Finally, we applied our new modeling approach to a case study area to evaluate its performance compared with that rendered by Epstein's heuristics method.

\section{Background}

Automatic planning of road networks is a very complex locational problem. Economically, a trade-off exists between minimizing the fixed costs (e.g., road construction, harvesting equipment, and transportation vehicles) and minimizing the variable costs (e.g., labor costs as a function of harvesting and transportation) (Stückelberger et al. 2006a). We first reviewed the traditional approaches taken in the field of forest road network design and then focused on methods that simultaneously optimized for harvesting systems and road layouts.

\subsection{Network design}

Before computer-aided approaches were developed in the 1970s, laying out a road network was a cognitive, time-consuming task that required both engineering skills and practical experience. Kirby (1973) introduced a linear programming approach that supported such planning for different objectives while Mandt (1973) described a shortest-path application for building roads that connected two specific points. Dykstra and Riggs (1977) then devised a method to assist in designing harvesting units, and used facility location theory to assign logging equipment. This problem had to be solved heuristically. The US Forest Service (Twito et al. 1987) developed a PLANS model for harvesting and road networks on large-scale topographic maps. This system functioned essentially as a simulator. Liu and Sessions (1993) presented a method for addressing a harvest-scheduling problem that determined the optimal set of necessary road segments and the year in which they were to be constructed. This challenge was met through a heuristics algorithm as well. A similar problem was addressed by Murray and Church (1995), in which the costs of road construction were included in the planning of forest operations. Although those costs required the introduction of a mathematical formulation, the problem was again solved heuristically. Similar efforts were made by Dean (1997), Murray (1998), and Clark et al. (2000).

Richards and Gunn (2000) optimized the concurrent scheduling of both harvesting and road construction. In that case, the road network was already set, but a heuristic tabu search algorithm was applied because of the complexity of the problem. Later, Anderson and Nelson (2004) developed a vector-based automatic road location model, in which a network was created by linking given landings with a shortest-path algorithm combined with heuristics algorithms. Compared with those former approaches, this new method enabled planners to implement a better road link design that also allowed for its application in steep terrain. Finally, Stückelberger et al. (2006a, 2006b, 2007) improved on this approach from Anderson and Nelson by mapping road-turning constraints (using a 48-Link pattern) and by introducing a generic road cost model based on a DEM and geotechnical layers. This technique by Stückelberger applied a Steiner tree heuristic in order to find a near-optimal solution for plotting a network between several defined road terminals. Another approach to the development of road layouts via DEM was later presented by Chung et al. (2008).

\subsection{Concurrent optimization of harvesting and road network layouts}

The problem class for identifying a mathematically optimized solution for both road construction and harvesting has been generally described by Balakrishnan et al. (1989). Labeled 
Table 1 Influence of road network design on three Cost Factors

\begin{tabular}{|c|c|c|c|c|}
\hline \multirow[t]{2}{*}{ Cost factor } & \multicolumn{3}{|l|}{ Switzerland } & \multirow{2}{*}{$\begin{array}{l}\text { Chile (Epstein } \\
\text { et al. 2006) } \\
\text { [USD per } \mathrm{m}^{3} \text { ] }\end{array}$} \\
\hline & Specific costs & $\begin{array}{l}\text { Cost per } \mathrm{m}^{3} \\
{\left[\mathrm{CHF} \text { per } \mathrm{m}^{3}\right]}\end{array}$ & $\begin{array}{l}\Delta \text { Variation } \\
\text { (average } \% \text { of } \\
\text { total costs) }\end{array}$ & \\
\hline $\begin{array}{l}\text { Construction and } \\
\text { maintenance }\end{array}$ & $175-350 \mathrm{CHF} / \mathrm{m}$ & $12-50$ & $38(\approx 32 \%)$ & $3.0-5.0$ \\
\hline Off-road trsp. & $\begin{array}{l}40 \mathrm{CHF} / \mathrm{m}^{3}(\mathrm{CY}), \\
120 \mathrm{CHF} / \mathrm{m}^{3}(\mathrm{H} .)\end{array}$ & $40-120$ & $80(\approx 67 \%)$ & $7.5-9.5$ \\
\hline \multirow{2}{*}{$\begin{array}{l}\text { On-road trsp. } \\
\text { (inside harv. unit) }\end{array}$} & \multirow[t]{2}{*}{$0.2 \mathrm{CHF} / \mathrm{km} / \mathrm{m}^{3}$} & $0.4(\varnothing 2 \mathrm{~km})$ & \multirow[t]{2}{*}{$0.8(\approx 1 \%)$} & 0.1 \\
\hline & & $1.2(\varnothing 6 \mathrm{~km})$ & & 0.3 \\
\hline
\end{tabular}

a "fixed-charge network design problem", it is known to be NP-hard. The most widely used approach has been PLANEX (Epstein et al. 1999, 2006), for which a Mixed Integer Linear Programming (MILP) model is utilized to minimize the costs of harvesting, machine installation, road construction, and road transport simultaneously. However, because real problems are very large, they must be addressed with a greedy heuristics algorithm. PLANEX was designed for plantation operations with yarding systems that require the construction of a few large landings with radial cable road patterns. As an alternative, CPLAN (Chung et al. 2004) also optimized simultaneously the assignment of cable-logging equipment and road link locations, which could then be solved with a heuristics algorithm. By contrast, Stückelberger et al. (2006b) introduced a road network optimization model that included the attractiveness for cable-yarding. However, that landing-attractiveness metric was a condensed value that allocated accessible, though overlapping, areas to each potential landing. This approach, although useful for influencing the location of a road between two nodes, was not appropriate for routing problems where the source node was unknown. Finally, in an attempt to improve PLANEX, Diaz et al. (2007) presented a tabu search metaheuristic that, with significantly shorter computational times, could produce better solutions than those provided by most state-of-the-art integer programming codes. Although already tested with various planning scenarios, this metaheuristic has not yet been evaluated within PLANEX.

\section{Model design and setup}

Our study objective was to develop an approach that concurrently minimized the costs associated with road construction and on-/off-road transport. This was accomplished by selecting a portfolio of road segment investments and by determining which parcels were to be harvested by cable-yarders or helicopters.

The strategy described here involved the formulation of a problem that remained as simple as possible, while still capturing its main decision elements. It also was designed to be implemented with commercial software tools already available. Three primary Cost Factors were considered: (1) Road Construction and Maintenance, (2) Off-road Transport, and (3) On-road Transport. To examine the influence of road network design on those factors, we generated several layout options and estimated their related transportation and road costs. For that we used a $4.3-\mathrm{km}^{2}$ harvesting unit with an annual increase in volume of $5 \mathrm{~m}^{3} / \mathrm{ha}$. From this we were to harvest approximately half of the timber over a rotation of 50 years ( $2 \%$ interest rate). The results of these considerations are summarized in Table 1. One 
extreme scenario included a dense road network (5.6 km long) that crossed some geotechnically difficult areas. For that, the average construction and maintenance costs would have been $350 \mathrm{CHF} / \mathrm{m}$, or $50 \mathrm{CHF} / \mathrm{m}^{3}$ calculated over the entire life cycle of the road network (CHF: Swiss Franc; 1 USD $\approx 0.9$ CHF). Because most areas could be accessed by cableyarder, however, off-road transport costs were usually low, about $40 \mathrm{CHF} / \mathrm{m}^{3}$. Another extreme scenario entailed a shorter road network $(2.8 \mathrm{~km})$ that avoided crossing those difficult zones (construction and maintenance costs: $175 \mathrm{CHF} / \mathrm{m}$ ). This resulted in infrastructure costs of $12 \mathrm{CHF} / \mathrm{m}^{3}$. However, in that case, $50 \%$ of the total area had to be harvested by helicopter, which increased the average off-road transport costs to about $80 \mathrm{CHF} / \mathrm{m}^{3}$. These two scenarios contrasted in their hauling distances by about $4 \mathrm{~km}$, which meant a difference of $0.8 \mathrm{CHF} / \mathrm{m}^{3}$.

Although those associated costs varied between layouts, we found that the network design greatly affected both Factors 1 and 2, accounting for $99 \%$ of the cost variation (Table 1). Therefore, we chose to ignore Factor 3 (On-road Transport) in our optimization model and accepted an error of about $1 \%$ in the worst case. We also calculated relative costs as defined by Epstein et al. (2006), and found that all showed a similar trend, i.e., the on-road costs within a project area were quite small relative to off-road and construction costs. This supported our decision not to include the costs of on-road transportation. However, the assumption taken here might not always be true. For example, if a road constructed for a small harvest unit is used to provide the main access to bigger areas where a large volume of timber exists, then on-road transportation costs might not be trivial.

\subsection{Conceptual model}

The harvesting process of wood is captured from standing trees (timber parcel) to a virtual pile at the interface to the planning unit. Thus, our conceptual model (Fig. 1) consisted of three subsystems:

First, the road network subsystem determined the locations of road segments and connected them to the superordinate network. The most appropriate road network design for steep terrain has been devised by Stückelberger et al. (2007). There, each grid cell is linked to 48 neighboring grid cells in 16 different directions. This representation requires one physical node to be split into 16 virtual nodes amounting to 16 nodes per grid cell. If one assumed a $10-\mathrm{m} \times 10-\mathrm{m}$ grid resolution and a project area of $5 \mathrm{~km}^{2}$, we would have needed $0.8 \times 10^{6}$ nodes and about $19.2 \times 10^{6}$ road links for our project. However, such a scenario would have been impossible to solve while concurrently optimizing a harvesting layout. Therefore, we proposed the following simplified network design. We limited the number of nodes that represented potential road terminals and junctions. The links (arcs) between these nodes depicted the road segments and the landing sites. The set of possible road segments and nodes indicated feasible ways for traversing that landscape. To link road segments in a node may have required a switchback. Because they are expensive to construct, we had to check whether each node necessitated a switchback and then include them in our model.

Second, the cable-yarding subsystem detected the timber parcels that could be accessed from a particular landing (each road segment was considered to be one landing unit) and then estimated the costs for the harvesting process.

Third, the aerial logging subsystem allowed us to introduce the option of using a helicopter for harvesting parcels that would be too expensive to access by a cable-yarder and road network. The cost incurred with such an aerial system also served as an upper marginal value for harvesting a unit via cable-yarding (which also included associated road-access costs). 


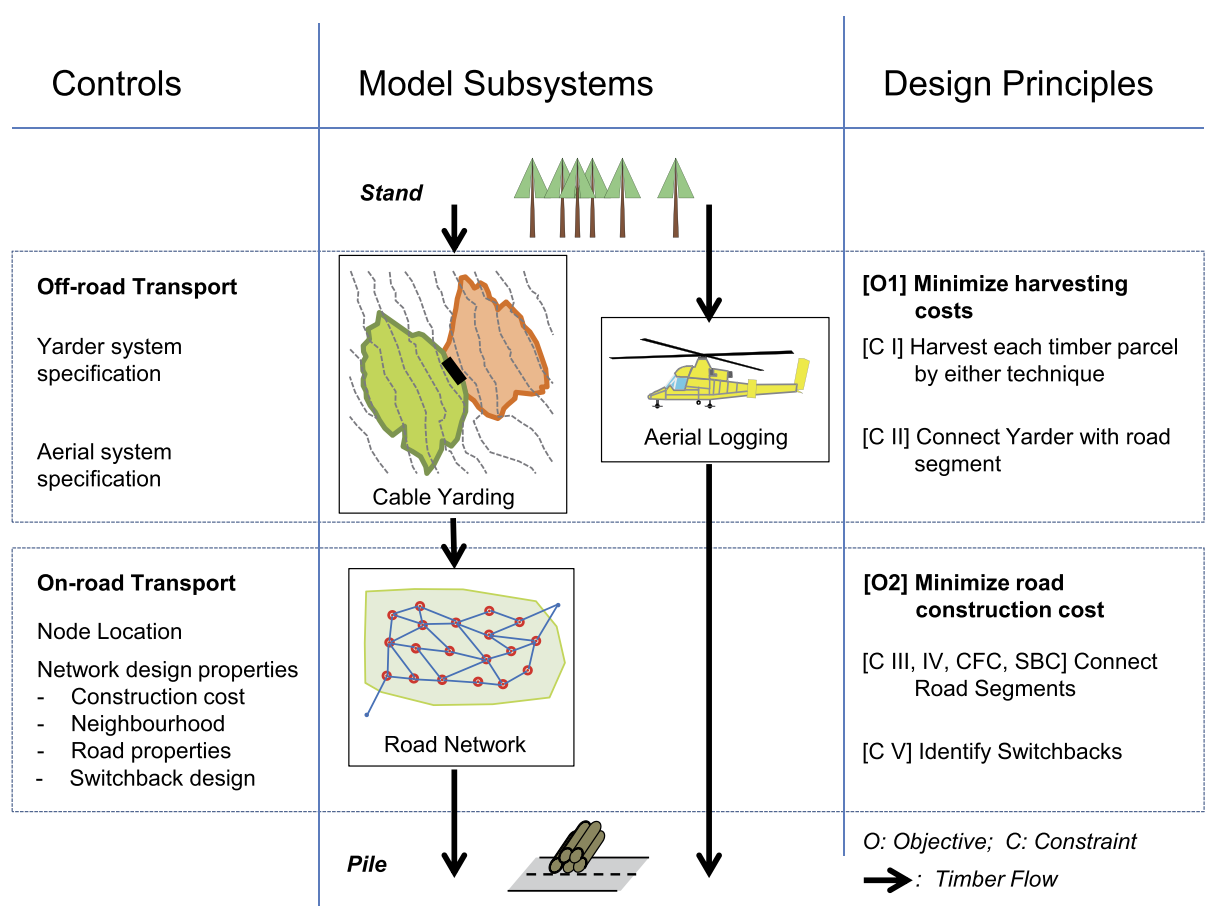

Fig. 1 Conceptual model, consisting of model subsystems (center), design principles (right), and controls (left)

\subsection{Analytical model}

To solve our network design problem, we developed a MILP model. We referred to it as an MRHCL (Minimum Road and Harvesting Cost Layout), which utilized the parameters shown in Fig. 2. Even though we considered only one yarding technology in this study, we generated a flexible model that could handle alternate methods.

\section{Notation}

$r, z$ index of road segment

$a, t$ index of nodes

$i \quad$ index of timber parcel

$b \quad$ index of off-road transportation technology

$y_{r}^{R S}$ " 1 " if road segment $r$ is constructed, " 0 " if not

$y_{a}^{S} \quad$ " 1 " if switchback in node $a$ is constructed, " 0 " if not

$x_{i b}$ " 1 " if timber parcel $i$ is harvested by technique $b$, " 0 " if not

$c_{r}^{R S}$ Construction cost of road segment $r, c_{r}^{R S}=c_{r-1}^{R S}$ for all $r \bmod 2=0$

$c_{a}^{S} \quad$ Construction cost for a switchback at node $a$

$c_{i b}$ Cost to harvest timber parcel $i$ by technique $b$

$G \quad\{b \mid$ Set of off-road transport technologies $\}, G=S \cup H$

$S \quad\{b \mid$ Set of cable-yarding technologies: Up-hill, Down-hill $\}, S \subset G$

$H \quad\{b \mid$ Helicopter harvesting technology $\}, H \subset G$

$R \quad\{r \mid$ Set of road segments $r\}, R=Q \cup P$ 


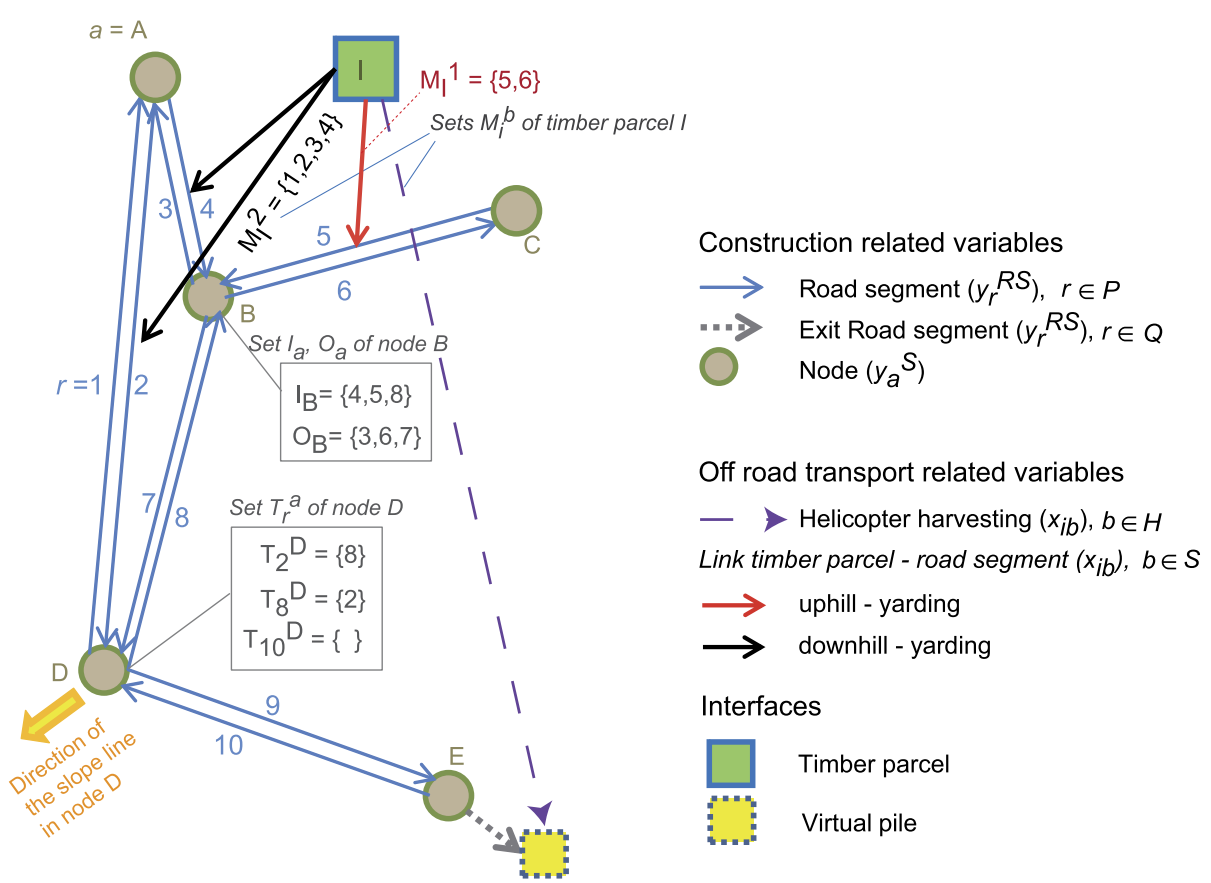

Fig. 2 Sets and parameters incorporated into our model

$Q \quad\{r \mid$ Set of road segments $r$ that are potential exits $\}, Q \subset R$

$P \quad\{r \mid$ Set of road segments $r$ between network nodes $\}, P \subset R$

$M_{i}^{b} \quad\{r \mid$ Set of road segments $r \in R$ that could reach parcel $i$ by technique $b\}$

$T_{r}^{a}\{z \mid$ Set of road segments $z \in P$ that could be linked with road segment $r \in P$ in node $a$ by construction of a switchback and $z \bmod 2=0\}$

$I_{a} \quad\{r \mid$ Set of road segments $r \in P$ that are a potential input flow link to node $a\}$

$O_{a} \quad\{r \mid$ Set of road segments $r \in R$ that are a potential output flow link from node $a\}$

The road design problem could essentially be displayed as a network in which all timber parcels had to be linked with a virtual pile. Our network consisted of several Types of arcs: (1) "timber parcel—road segment", (2) "road segment", and (3) "helicopter harvesting" (Fig. 2). If we assumed a typical problem size of $5 \mathrm{~km}^{2}$ with 2000 timber parcels $(50 \mathrm{~m}$ $\times 50 \mathrm{~m}$ ), 60 nodes, and 800 road segments (by which each could access an average of 200 parcels), then we had about $1.6 \times 10^{5}$ arcs of Type 1 . Here, we introduced a set-cover formulation (Eq. (3)) and assumed that the yarding costs for a parcel depended only upon direction (uphill/downhill). Thus, we could reduce the number of Type-1 variables to 4000 (two variables per parcel, one for downhill and one for uphill) or by a factor of 25. This decreased the calculation time significantly. Such a set-cover formulation has also been applied in related fields, a good example being reserve site selection as described by Church et al. (2000). Because we did not know the direction in which on-road transport of the wood would take place, we split one physical road segment $r \in P$ into two virtual segments called indices $r$ and $r-1$, where $r \bmod 2=0$ and $r-1$ was directed opposite to $r$. Road segments $r \in Q$ were defined only in the out-going direction from their corresponding node. 


\section{Objective function}

Our objective was to minimize, simultaneously, the costs of road construction (segments, switchback) and harvesting (yarder, helicopter).

$$
\operatorname{Min} \sum_{r \in R} c_{r}^{R S} y_{r}^{R S}+\sum_{a} c_{a}^{S} y_{a}^{S}+\sum_{b \in G} \sum_{i} c_{i b} x_{i b}
$$

\section{Constraints}

Each timber parcel $i$ had to be harvested once, by either helicopter or one of several cablebased techniques:

$$
\sum_{b \in G} x_{i b}=1 \quad \text { for all } i
$$

If parcel $i$ was to be harvested by cable technique $b \in S$, at least one road segment had to be built that could access parcel $i$ via that technique:

$$
\sum_{r \in M_{i}^{b}} y_{r}^{R S} \geq x_{i b} \quad \text { for all } i, b \in S
$$

Only one directed road segment of the pair $r$ and $r-1$ could be built:

$$
y_{r}^{R S}+y_{r-1}^{R S} \leq 1 \quad \text { for all } r\{r \mid r \bmod 2=0\}, r \in P
$$

To promote road connectivity, we had to ensure that, if there was an input flow link to node $a$, at least one output flow link had to exist from node $a$ :

$$
y_{r}^{R S} \leq \sum_{z \in O_{a}} y_{z}^{R S} \quad \text { for all } r \in I_{a}, \text { for all } a
$$

If two road segments $(r, z \in P)$ were linked at node $a$, and if that status required a switchback, then the switchback had to be built:

$$
\begin{aligned}
& y_{r}^{R S}+y_{r-1}^{R S}+y_{z}^{R S}+y_{z-1}^{R S}-y_{a}^{S} \leq 1 \\
& \quad \text { for all } r \in P \text { and } r \bmod 2=0, \text { for all } a, \text { for all } z \in T_{r}^{a}
\end{aligned}
$$

non-negativity and integrality of the variables:

$$
y_{r}^{R S} \in\{0,1\} ; \quad y_{a}^{S} \in\{0,1\} ; \quad x_{i b} \geq 0
$$

Note that $x_{i b}$ was defined as a binary variable in the model notation, which required that one harvesting option be selected for each timber parcel. Even without this restriction, $x_{i b}$ was assumed to be a binary value in the optimum solution. First, Eq. (2) defined an upper bound of 1 for $x_{i b}$. If $x_{i b}$ was not binary for parcel $i$, one had to assume fractional values for at least two different transportation options $b$. Then, Eq. (3) could imply that multiple transportation infrastructures (road segments) had to be built for that parcel, which would result in a higher total cost. To minimize the harvesting cost in Eq. (1), we chose the option with minimum $v_{i b}$ value and assigned a binary value to the corresponding $x_{i b}$. Relaxation of the binary restriction in Eq. (7) was important because this maneuver improved the computational efficiency of the model.

Problems similar to the types described here can involve routing, for which one must minimize length while maximizing demand coverage. An example is provided by Current 
et al. (1985), who refer to it as a maximum covering shortest path problem (MCSP). Another example has been described by Matisziw et al. (2006), who labeled this as a maximum covering route extension problem (MCREP). One state that must be considered when solving such problems is the occurrence of subtours. Therefore, constraints that eliminate such subtours are often necessary when using integer programming techniques.

\subsection{Model set-up}

\subsubsection{Geographical database and grid resolution}

A database, represented as $10-\mathrm{m} \times 10$-m raster cells by default, is used to provide geographical information. It has five layers: (1) DEM, (2) volume of timber to be harvested, (3) geotechnical classification of the subsoil, (4) obstacles to cable-yarding (e.g., highvoltage power lines), and (5) the stream network. A layer for any existing road network is imported as a vector-defined dataset. Layer 2 can be clustered into larger units, such as those aggregated into a raster of $20 \mathrm{~m} \times 20 \mathrm{~m}, 30 \mathrm{~m} \times 30 \mathrm{~m}$, etc. The term "Timber Parcel Cluster Factor", or TPCF, indicates the amount of clustering needed. For example, TPCF = 2 means that resolution is $20 \mathrm{~m} \times 20 \mathrm{~m}$. The choice of $T P C F$ has a remarkable influence on computational efficiency; values between 5 and 20 provide the best ratios of efficiency to accuracy of the results. Numerous publications have described how spatial structure and resolution can impact the solution characteristics of a model. For example, O'Sullivan and Unwin (2002) have referred it to as a Modifiable Areal Unit Problem (MAUP).

\subsubsection{Candidate nodes}

Nodes indicate potential terminals and junctions within a network, and are placed by experts who apply the following criteria:

(1) Nodes should be sited at terrain points where conditions are appropriate for constructing a switchback or junction. If, however, the terrain is generally too steep for this, a node can be set instead. In that case, however, this placement acts only as a link between two road segments (without any switchback) or as a terminal.

(2) Nodes should initially be dispersed uniformly over the planning unit.

More precise positioning can then be made by an algorithm that detects areas of flat terrain within the neighborhood (using switchback cost as the indicator). Here, our algorithm used a search radius ( $r_{n s}$, or radius nodes search) that ranged from 20 to $50 \mathrm{~m}$ to identify those flat regions; $20 \mathrm{~m}$ allowed us to generate the best results.

The number of nodes has a marked effect on calculation efficiency. For the scenario presented here, we set that number at 20 to 25 nodes per $\mathrm{km}^{2}$. Their positions and numbers are the most important determinations an engineer must make when designing a possible network. Because the harvesting and roading problem can be solved efficiently with optimization software, it is logical that one first define a network and solve the harvesting and roading model, then re-set those nodes (add, remove, or adjust) and run the model again, repeating this process with the goal of producing an improved solution.

\subsubsection{Road network topology}

After the nodes are set, the network topology must be defined. Linking each node with each other node leads to an enormous number of possible road segments, which grows according 
to the function $n *(n-1) / 2$, where $n$ is the number of nodes. Thus, it is logical to reduce the amount of possible road segments by considering only those that occur between neighboring nodes. To do this here, we calculated two distance metrics-a weighted Euclidean distance involving elevation, $\Delta d_{1}$, and an unweighted Euclidean distance not involving elevation, $\Delta d_{2}$ (Eq. (8) and Eq. (9)). Those distances were computed from each node to every other node. They added road segment links from a given node to the NS-closest (NS: Neighborhood Size) nodes based upon the $\Delta d_{1}$ distance, as well as links to the $N S$-closest nodes based upon the $\Delta d_{2}$ distance. It was possible that the closest nodes from a given node at either distance would be the same, and that, at the very least, there could be $N S$ links defined from a given node. Here, we set $N S=10$ as our default value because previous experience had proven it to be most appropriate.

$$
\begin{gathered}
\Delta d_{1}=\sqrt{\Delta x^{2}+\Delta y^{2}+\left(10 \Delta z^{2}\right)} \\
\Delta d_{2}=\sqrt{\Delta x^{2}+\Delta y^{2}}
\end{gathered}
$$

where

$\Delta x: x$-coordinate difference between two nodes [m]

$\Delta y: y$-coordinate difference between two nodes [m]

$\Delta z$ : elevational difference between two nodes [m]

\subsubsection{Road segment layout}

Our physical layout of each road segment was determined by applying the methodology of Stückelberger et al. (2006a, 2007). A layout is defined through nodes located at the ends and waypoints in-between; the distance between each waypoint is related to the link pattern, i.e., 10 to $50 \mathrm{~m}$. Stückelberger's approach considers spatial variability and road-turning constraints. Here, we used an implied network between two nodes and employed a 48directional link pattern and 16 different directions. We then identified those waypoints and the cost of a single road segment connecting two nodes by searching for the least-cost path for each arc within our network. This calculation was based on a shortest-path algorithm (Bellmann 1958). An example of a road network containing 75 nodes and 274 road segments $(N S=5)$ is presented as a map of the topological network in Fig. 3a and as a physical layout of the road segments in Fig. 3b.

\subsubsection{Switchback in nodes}

At this important step, we had to focus on how road segments could be linked to nodes within the network because designers must know whether a switchback is required when connecting several segments in a node (junction). This component is vital because the costs of switchback construction are a main cost-driver in developing a road network over steep terrain. Here, we assumed that a switchback was needed if two segments entering the node from the same side of the slope line were linked (Fig. 4). A single road segment with 16 potential directions also necessitated 16 potential input and output directions in a node to connect with a particular segment. The direction of the slope line was ascertained by searching the maximum slope gradient to the adjacent cells. Our eight adjacent cells meant eight potential directions for the slope line. Switchback construction costs were derived according to the method of Stückelberger et al. (2007). 

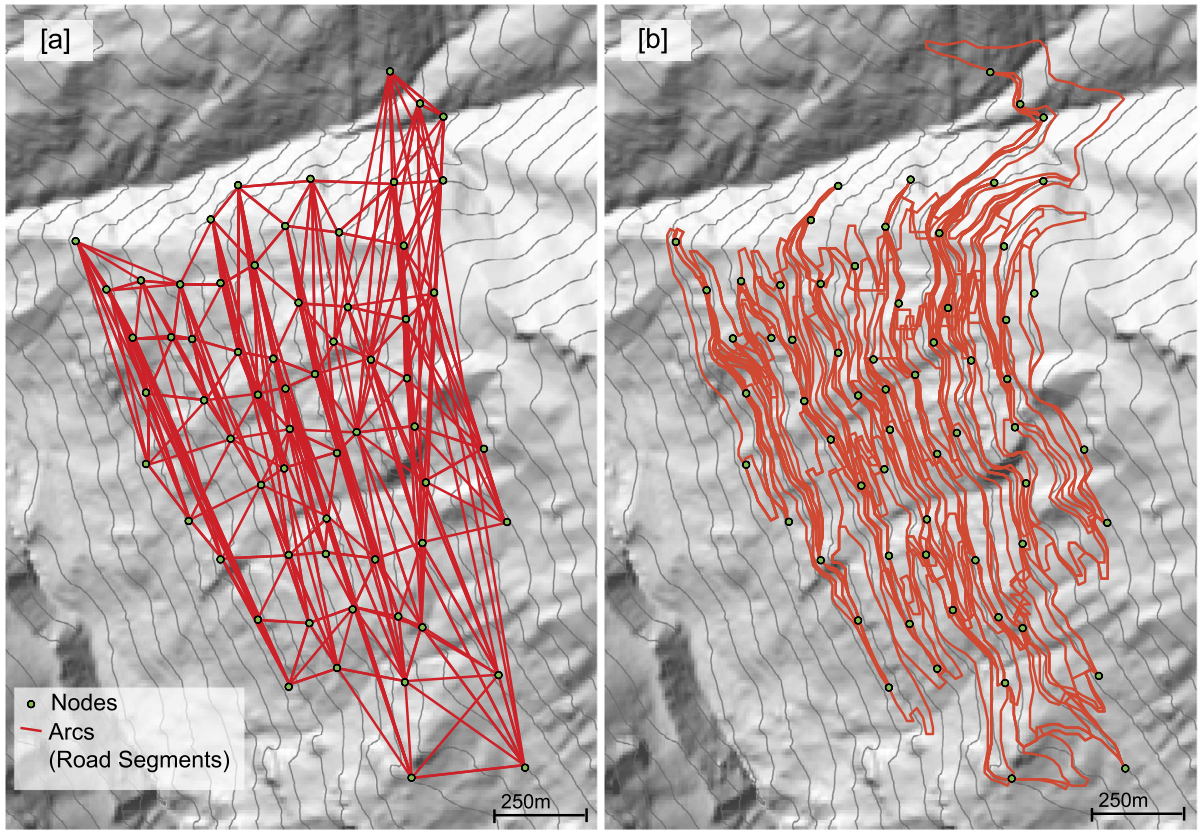

Fig. 3 (a) Topological road network containing 75 nodes and 274 road segments $(N S=5)$. (b) Physical layout of the road network showing the shortest-path segments. (C) 2011 swisstopo (JD100042)

Fig. 4 Representation of a node with 8 potential directions for the slope line and 16 potential directions for road segments entering the nodes. Segment directions are classified as code " 2 " for directions in the slope line and as code " 0 " or " 1 " for the left or right side of the line. Linking two segments with code "0", e.g., $i$ and $j$, or two road segments each with code " 1 ", requires that a switchback be built, whereas a linking between $l$ and $k$ does not

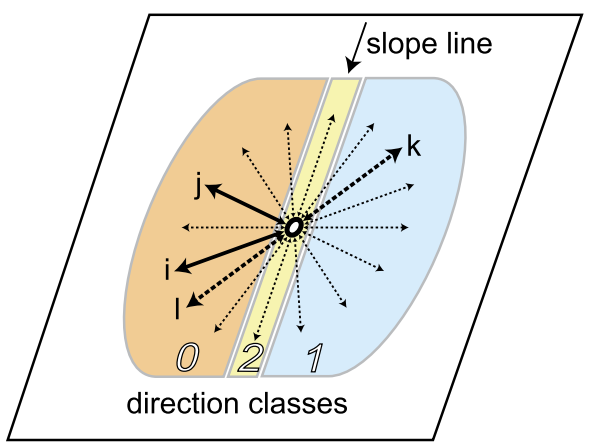

\subsubsection{Cable-yarder coverage analysis}

We defined each road segment as a landing element. The cable-yarder coverage of such a "road segment landing" element was defined as the amount of coverage for individual waypoints. The assumption made here was that yarding machines could be installed at all waypoints along the forest road. To evaluate the timber parcels that could be accessed from a "road segment landing", we applied the following:

1. For each waypoint of the road segment, we could install 32 radial lines and check the maximum feasible distance when building a cable road for each line. That distance depended upon the allowable number of intermediate supports, properties of the yarding 
system, and terrain properties. To make this process as efficient as possible, we used the cable-mechanics assumptions of Pestal (1961).

2. If the center of a parcel was within a certain distance of the skyline (default $=25 \mathrm{~m}$ ), then the parcel was defined as accessible.

3. Parcels that could be accessed from one landing (road segment) were those that utilized single waypoints.

We defined clustered timber parcels as those that were connected to a road segment if a certain percentage within that cluster was accessible from a given segment (default $>50 \%$ ).

\subsubsection{Off-road transport costs}

Yarding costs can include those for felling, cable-based extraction from the parcel to the forest road, processing of the tree (trimming limbs and bucking), and set-up and dismantling of the yarding system. Although processing is neither distance-dependent nor reliant upon the harvest technology selected for a particular site, we considered it here because this step is included in productivity models where it is used to describe properly the processing and transport of timber from the stump to a virtual pile outside of the planning unit. Our costs for felling, yarding, and processing were estimated according to a model described by Stampfer et al. (2003). Costs for system set-up and dismantling were determined via another model from Stampfer et al. (2006). Afterward, we simplified those estimations and assumed that logging costs were constant for each parcel. The exception was that up-hill and down-hill logging were differentiated for a particular parcel. This assumption allowed us to reduce the number of decision variables so that we could employ a more efficient problem formulation that included set-cover constraints (Eq. (3)). Yarding distance does not greatly affect productivity when operating state-of-the-art tower yarders (e.g., Mounty 5000 from Konrad). In our test area, the variable harvesting costs for a yarding distance of $100 \mathrm{~m}$ were 40 to $50 \mathrm{CHF} / \mathrm{m}^{3}$; they increased by about $2 \mathrm{CHF} / \mathrm{m}^{3}$ for each additional $100 \mathrm{~m}$ of distance (Stampfer et al. 2003). Therefore, the error introduced by this assumption was quite small.

The process "Helicopter Logging", comprising the steps of felling, transport, and processing, was analyzed according to the model of Heinimann and Caminada (1996). Here, we assumed that the entire planning unit could be reached aerially and that helicopter-harvesting costs were constant for all parcels. Practical limitations on what can be harvested by helicopter may sometimes arise because the transportation distance is great between the parcel and the pile. However, the relatively small dimensions of our current project area made those limitations irrelevant here.

\subsection{Life-cycle cost model}

The costs for a life-cycle system, as described in our project, were those associated with road construction, road maintenance, and harvesting. Because the last two factors are periodic costs that accrue over time while construction costs are incurred only at the beginning of a cycle, those components had to be made comparable. To normalize them in-time, we took the net present value (NPV) approach, assuming a project life cycle of 50 years, an interest rate of $2 \%$, and a constant share in maintenance and harvesting costs per year (Park and Sharp-Bette 1990). Equation (10) was used for construction-related variables, such as $c_{r}^{R S}$, $c_{a}^{S}$, while Eq. (11) was applied for the off-road transport-related variable $c_{i b}$. All of those variables were detailed in Sect. 3.2.

$$
C_{c \& m}=C_{c}+C_{m} *\left(\frac{1-(1+i r)^{-N}}{i r}\right)
$$




$$
c_{i b}=C_{i b} * \frac{V_{i}}{N} *\left(\frac{1-(1+i r)^{-N}}{i r}\right)
$$

where

$C_{c \& m}$ Total construction and maintenance costs (per NPV) for a road segment or switchback $[\mathrm{CHF}]$

$C_{c} \quad$ Construction cost for a road segment or switchback [CHF]

$C_{m} \quad$ Average annual maintenance cost $[\mathrm{CHF}]$

$c_{i b} \quad$ Cost (NPV) for harvesting timber parcel $i$ by mean $b[\mathrm{CHF}]$

$C_{i b} \quad$ Cost to harvest timber parcel $i$ by mean $b\left[\mathrm{CHF} / \mathrm{m}^{3}\right]$

$V_{i} \quad$ Volume to harvest in timber parcel $i$ during the amortization period $\left[\mathrm{m}^{3}\right]$

$N$ Amortization period of the road (in the present model, $=50$ years)

ir Annual interest rate (in the present model, $=2 \%$ )

\subsection{Subtour breaking}

If we ran the model as formulated in Sect. 3.2, we generated a solution that contained a subtour of road segments as illustrated in Fig. 5. If the optimal solution to the above model included subtours, we then considered two constraint options that could be used to eliminate them: Subtour-Breaking Constraints (SBC) and Continuous-Flow Constraints (CFC).

\section{Additional notation}

$k \quad$ Index of the set of contiguity nodes

$R^{k}\left\{r \mid\right.$ Set of road segments $r \in P$ that started or ended in the set of contiguity nodes $\left.J^{k}\right\}$

$J^{k}\{a \mid$ Set of contiguity nodes $\}$

$e^{k}$ " 1 " if one road segment has been built that starts or ends in node $a \in J^{k}$; " 0 " otherwise

$u_{r}^{k} \quad$ " 1 " if road segment $r \in P$ was activated for the contiguity network; " 0 " otherwise

$m_{a}^{k}$ " 1 " if node $a \in J^{k}$ was the start node of contiguity network; " 0 " otherwise

The first option was to introduce a set of SBCs, a concept first outlined by Miller et al. (1960). Here the solution had to be checked, subtour-breaking constraints added, and the model re-solved if necessary. However, because another subtour could have occurred in the next iteration, this constraint alone did not guarantee a subtour-free solution.

The second option was to introduce a set of CFCs. These types of constraints were first described by Church and Cova (2000). Through their application, one could be confident that a path existed within a cluster between two specified nodes. We adapted those constraints to ensure that a path occurred between a set of starting nodes $J^{k}$ ('contiguity nodes') and potential exit road segments $r \in Q$. If one node within the set of contiguity nodes was selected in the solution for the road network, then that node also had to be linked by a pathway of selected arcs to an exit road segment. If necessary, several sets of contiguity nodes (labeled $k$ ) could be defined. For each set of $k$, the constraints were determined as follows:

If a road segment $r \in R^{k}$ were to be built that was linked with a contiguity node $a \in J^{k}$, then the contiguity constraints had to be activated.

$$
y_{r}^{R S} \leq e^{k} \quad \text { for all } r \in R^{k}
$$

If the contiguity constraints were active, one of the road segments $r \in R^{k}$ that was linked with a contiguity node had to be built.

$$
e^{k} \leq \sum_{r \in R^{k}} u_{r}^{k}
$$


Fig. 5 Road-layout solution calculated without contiguity constraints. Because it contains subtours, not all segments are connected to the exit node. To avoid having such subtours, one option is to introduce CFCs. If one node belonging to $\mathrm{CFC}$ Class $\mathrm{m}$ is selected for the solution, then at least one of the nodes in that Class must be connected to the exit junction. (C) 2011 swisstopo (JD100042)

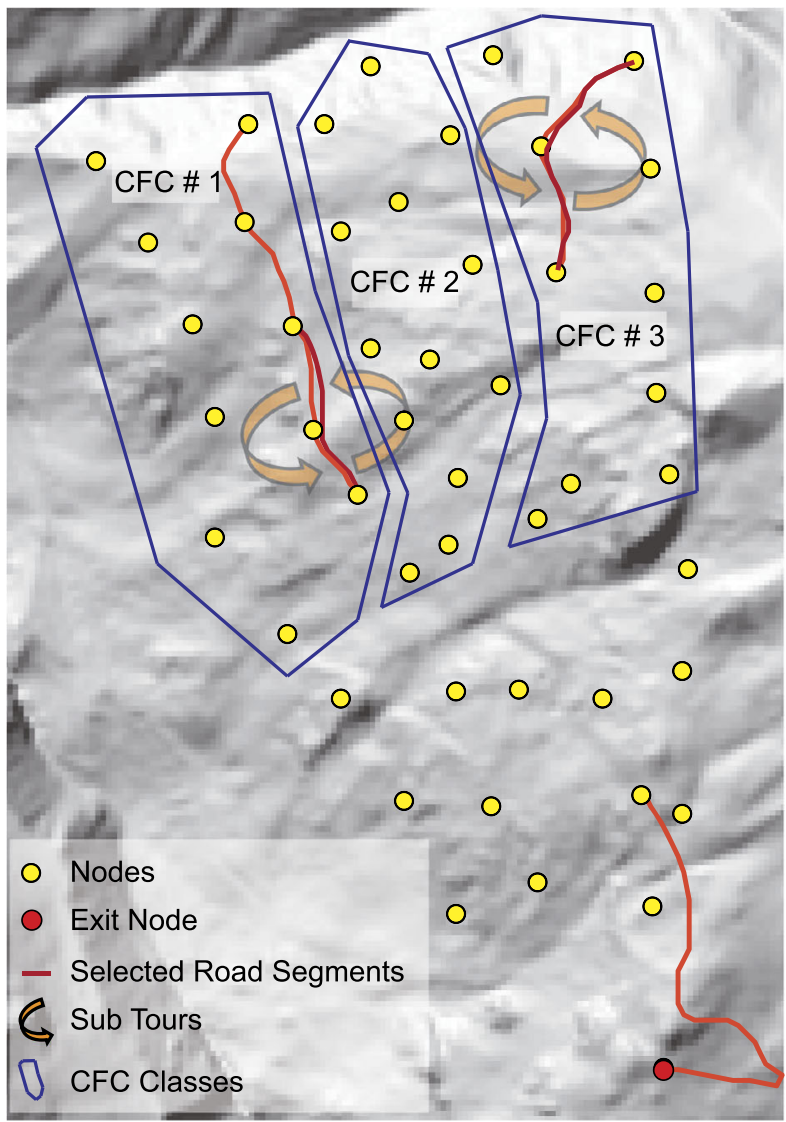

Flow balance in the potential start nodes

$$
m_{a}^{k}+\sum_{r \in I_{a}} u_{r}^{k}=\sum_{r \in O_{a}} u_{r}^{k} \quad \text { for all } a \in J^{k}
$$

Flow balance in the nodes (except for start nodes):

$$
\sum_{r \in I_{a}} u_{r}^{k}=\sum_{r \in O_{a}} u_{r}^{k} \quad \text { for all } a \text { except } a \notin J^{k}
$$

If the contiguity network were to be activated, this network had to have one start node.

$$
e^{k}=\sum_{a \in J^{k}} m_{a}^{k}
$$

If the contiguity network were to be activated, one exit road segment had to exist.

$$
e^{k}=\sum_{r \in Q} u_{r}^{k}
$$

If the contiguity road segment were to be activated, the corresponding road segment had to be built.

$$
u_{r}^{k} \leq y_{r}^{R S} \quad \text { for all } r \in R,
$$


non-negativity and integrality of the variables:

$$
e^{k} \in\{0,1\} ; \quad u_{r}^{k} \in\{0,1\} ; \quad m_{a}^{k} \in\{0,1\}
$$

The use of CFCs had to be expertly selected. As a first step, we ran the model without any contiguity constraints. If we obtained a solution with subtours, we then chose the contiguity nodes manually, and positioned those sets ( 1 to $k$ ) according to the following rules:

(1) Contiguity nodes were selected at the nodes surrounding a subtour identified from the current solution. For each subtour, a different set of contiguity nodes was used.

(2) If the optimal solution had several branches in its road network, then the area covered by one set of contiguity nodes should be crossed by only a single road branch. In most cases, the expert could predict how a good solution would appear.

As an example, in our test case, we obtained a solution that had subtours such as those in Fig. 5. We then selected three different sets of contiguity nodes to achieve a subtour-free solution.

Overall, our computational experience showed (cf., Model Application and Results section) that, even when SBC worked, its product was not significantly better than that obtained via the CFC approach.

\subsection{Heuristics procedure}

We introduced a heuristic for two reasons: (1) to have a comparison value for demonstrating the benefits of our model, and (2) to generate a good starting solution for our MRHCL optimization. This meant that the nodes generated in the heuristics solution were added to the expert-defined nodes before (re-)solving MRHCL. This approach has been tested in other areas of optimization by Rosing and ReVelle (1997) and Church (2008). Here, we applied a greedy heuristic that was used in PLANEX Software (Epstein et al. 2006). In doing so, we made the following modifications:

(1) Potential landings were set on a 40-m $\times$ 40-m grid that was uniformly dispersed across the entire planning unit.

(2) The number of machines was restricted to one type.

(3) To calculate road-construction costs, we used the methodology of Stückelberger et al. (2007), considering the spatial variability of the terrain.

\subsection{Assessment metric for the objective function}

We developed a reference function to calculate the complete objective value of the obtained solution. In contrast to the MRHCL model, this function included (1) a cost function that depended on distance and direction (uphill, downhill) to estimate the expense of yarding, and (2) the cost for on-road transport (truck) to a defined location outside the perimeter of the planning area subject to layout. We applied this same reference function in the MRHCL and heuristics approaches.

\section{Model application and results}

The purpose of our model application was to (1) demonstrate the efficacy of the new MRHCL model in solving realistically sized problems, (2) compare our MRHCL approach 
Table 2 Properties and parameter values for Problems I and II

\begin{tabular}{lllll}
\hline & $\begin{array}{l}\text { Harvesting cost } \\
\text { with helicopter } \\
{\left[\mathrm{CHF} / \mathrm{m}^{3}\right]}\end{array}$ & $\begin{array}{l}\text { Max. length } \\
\text { cable yarder }[\mathrm{m}]\end{array}$ & $\begin{array}{l}\text { Access roads } \\
\text { [number of } \\
\text { connections }]\end{array}$ & $\begin{array}{l}\text { Area of timber parcels not } \\
\text { accessible from existing } \\
\text { roads [ha] }\end{array}$ \\
\hline Problem I & 140 & 600 & 3 & 251 \\
Problem II & 240 & 400 & 1 & 345 \\
\hline
\end{tabular}

with the state-of-the-art heuristics method introduced by Epstein et al. (2006), and (3) investigate the quality of the results within a real-world application. This new model was implemented in Matlab, using the IBM CPLEX 11.2 Optimization package to solve each optimization problem.

\subsection{Test area}

The test area (433 ha) was located on the central slopes of the Swiss Alps in the region of Evolène (Canton of Valais; UTM Coordinates: 46.13536, 7.479286). We formulated two problem scenarios for harvesting $70,727 \mathrm{~m}^{3}$ of wood. Problem I corresponded to an actual situation: the community of Evolène was going to construct a new forest road to make the defined planning unit accessible for harvesting. The parameter values conformed to this real project. By contrast, Problem II was based on a slightly modified set of assumptions. Here, we established the maximum length of the cable road at $400 \mathrm{~m}$. We assumed only one access road and we set a penalty of $100 \mathrm{CHF} / \mathrm{m}^{3}$ for helicopter harvesting. This problem was introduced to check whether the model could find a non-trivial, optimal layout that involved at least two parallel branches. According to expert estimations by a district forest officer, the average yarding cost was $70 \mathrm{CHF} / \mathrm{m}^{3}$ for up-hill logging and $80 \mathrm{CHF} / \mathrm{m}^{3}$ for down-hill logging. The average cost for road construction was about $370 \mathrm{CHF} / \mathrm{m}$. Other properties and parameter values for Problems I and II are shown in Table 2. The relative optimality criterion was set to $10^{-4}$ (OptCR in "CPLEX", EPGAP in "Tomlab") and the absolute optimality criterion was set to $10^{-6}$ (OptCA/EPAGAP). Although the optimality criterion was not 0.0 , in most cases the optimal integer solution was detected.

\subsection{Problem I}

Here, we first solved the heuristic and then added the nodes generated in that solution to the expert-defined nodes before solving the problem by our MRHCL approach. We did this because the nodes in the heuristics approach were set on a 40-m $\times 40-\mathrm{m}$ grid (total of 2764 nodes; Fig. 6a, b). By comparison, the MRHCL approach called for only 65 expert-defined nodes, which resulted in a limited solution space. When introducing the nodes that were selected in the heuristics solution to the expert-defined nodes, we had to ensure that the MRHCL objective value was at least as good as that achieved heuristically. We executed the calculations in the following way (\# refers to the value listed in Table 3):

(1) MRHCL was solved with the expert-defined nodes only (\#2, Table 3; Fig. 6c). This solution objective was worse than the heuristics solution.

(2) Nodes from the heuristics solution were added to the expert-defined nodes. When MRHCL was re-solved (\#3, Table 3; Fig. 6d, Fig. 7), it achieved the same solution as that gained from the heuristics procedure. 


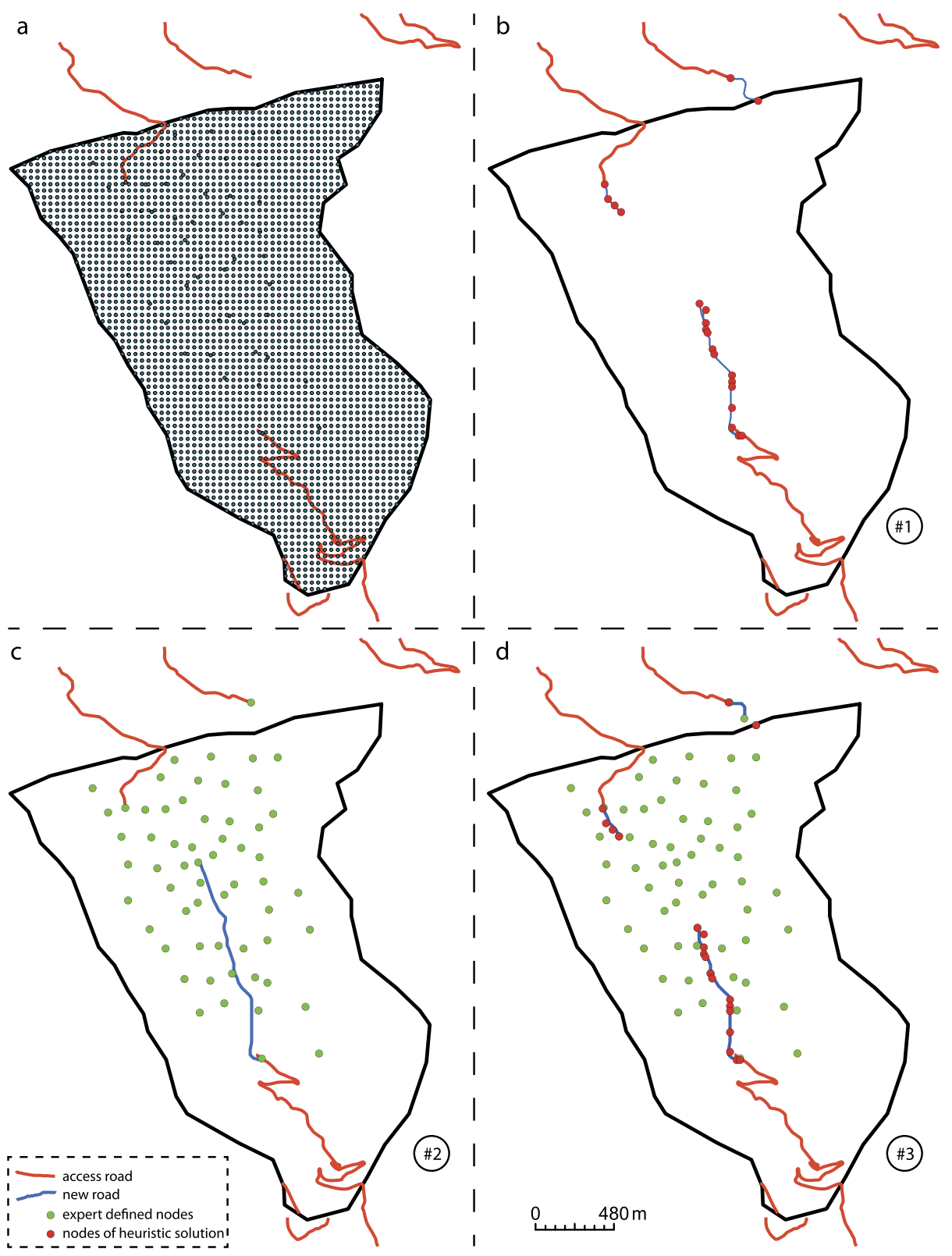

Fig. 6 Solution-finding process for Problem I. [a]: Nodes set on a 40-m $\times 40-\mathrm{m}$ grid as a basis for the heuristics approach. [b]: Solution from the heuristics approach with nodes is used in the heuristics solution. [c] MRHCL approach solved with expert-defined nodes only. [d] MRHCL approach solved based on expert-defined nodes and nodes generated by the heuristics solution

(3) Node positions were slightly adjusted with an algorithm that detected areas of flat terrain (cf., Sect. 3.3); we considered an $r_{n s}$ of $20 \mathrm{~m}$ (\#5, Table 3). The resulting MRHCL solution was no better than that obtained heuristically. 
Table 3 Numerical results and procedural steps for solving two defined problems. For Problem I, heuristic and MRHCL approaches delivered the same solution; for Problem II, the latter approach produced a $7 \%$ better objective value

\begin{tabular}{|c|c|c|c|c|c|c|c|c|c|c|}
\hline $\begin{array}{l}\text { No. } \\
(\#)\end{array}$ & Prob. & Method & $\begin{array}{l}\text { Cont. } \\
\text { constr. }\end{array}$ & Node & $\begin{array}{l}\text { No. } \\
\text { of } \\
\text { nodes }\end{array}$ & $\begin{array}{l}\text { Cluster size } \\
(T P C F)\end{array}$ & $\begin{array}{l}\text { Node search } \\
\text { radius (rns) } \\
\text { [m] }\end{array}$ & $\begin{array}{l}\text { Calc time } \\
\text { only opt. } \\
\text { [s] }\end{array}$ & $\begin{array}{l}\text { Obj. val. } \\
{[\mathrm{CHF}]}\end{array}$ & $\begin{array}{l}\text { Gap } \\
{[\%]}\end{array}$ \\
\hline 1 & I & Heur & - & - & - & - & - & 211 & $4,414,100$ & 0.0 \\
\hline 2 & I & MRHCL & SBC & basic & 65 & 5 & 0 & 217 & $4,614,600$ & 4.5 \\
\hline 3 & I & MRHCL & SBC & re-set & 75 & 5 & 0 & 246 & $4,414,100$ & 0.0 \\
\hline 4 & I & MRHCL & CFC & re-set & 75 & 5 & 0 & 945 & $4,414,100$ & 0.0 \\
\hline 5 & I & MRHCL & SBC & re-set & 75 & 5 & 20 & 742 & $4,436,277$ & 0.5 \\
\hline 6 & II & Heur & - & - & - & - & - & 276 & $7,334,200$ & 0.0 \\
\hline 7 & II & MRHCL & $\mathrm{CFC}$ & basic & 60 & 20 & 0 & 27,978 & $7,247,300$ & -1.2 \\
\hline 8 & II & MRHCL & CFC & re-set I & 56 & 20 & 0 & 14,496 & $6,990,696$ & -4.7 \\
\hline 9 & II & MRHCL & $\mathrm{CFC}$ & re-set II & 43 & 20 & 0 & 3,254 & $6,958,779$ & -5.1 \\
\hline 10 & II & MRHCL & $\mathrm{CFC}$ & re-set II & 43 & 15 & 20 & 258 & $6,835,200$ & -6.8 \\
\hline 11 & II & MRHCL & $\mathrm{CFC}$ & re-set II & 43 & 5 & 20 & 6,238 & $6,835,200$ & -6.8 \\
\hline
\end{tabular}

We further applied two kinds of contiguity constraints-SBC and CFC. Utilizing both, we were able to solve the MRHCL problem to optimality, although CFCs required more computational effort, $945 \mathrm{sec}$ versus $246 \mathrm{sec}$ (\#4 in Table 3). In all tested cases the optimum solution was detected within $15 \mathrm{~min}$. CPLEX solved all MRHCL approaches to optimality. The difference in goodness between solutions was caused by the varying numbers and positions of available nodes, resulting in a different solution space.

\subsection{Problem II}

Here we also first solved the problem according to heuristics and MRHCL, based on a set of initial expert-defined nodes. Because the heuristics approach detected only a trivial solution (Fig. 9b; \#6 in Table 3) that was worse compared with MRHCL, we did not add the nodes generated by the heuristics solution to the expert-defined nodes. Instead, we re-set the initial expert-defined nodes. We then proceeded in the following way:

(1) MRHCL was solved with expert-defined nodes (\#7 in Table 3, Fig. 8a). The solution called for two road branches and achieved a better objective value than from the heuristics solution.

(2) Re-setting the initial expert-defined nodes meant aggregating them around the road branches obtained from the current solution, while thinning the nodes in other areas, thereby improving the objective value (\#8, Fig. 8b).

(3) Step 2 was repeated to improve our objective value (\#9, Fig. 8c).

(4) Node positions in the current solution were slightly adjusted with an algorithm that detected areas of flat terrain and considered an $r_{n s}$ of $20 \mathrm{~m}$. This again improved the objective value (\#10,\#11). The resultant road layout is illustrated in Figs. 8d and 9a.

The MRHCL approach led to a $7 \%$ better objective value compared with the heuristics solution, at a savings of 499,000 CHF. We also tested SBCs and CFCs. When applying the former, we were unable to obtain a subtour-free solution. Therefore, we used CFCs. The calculation time was rather long, depending upon the parameter settings within CPLEX, and required between $4 \mathrm{~min}$ and $8 \mathrm{hrs}$ to solve the problem to optimality. 


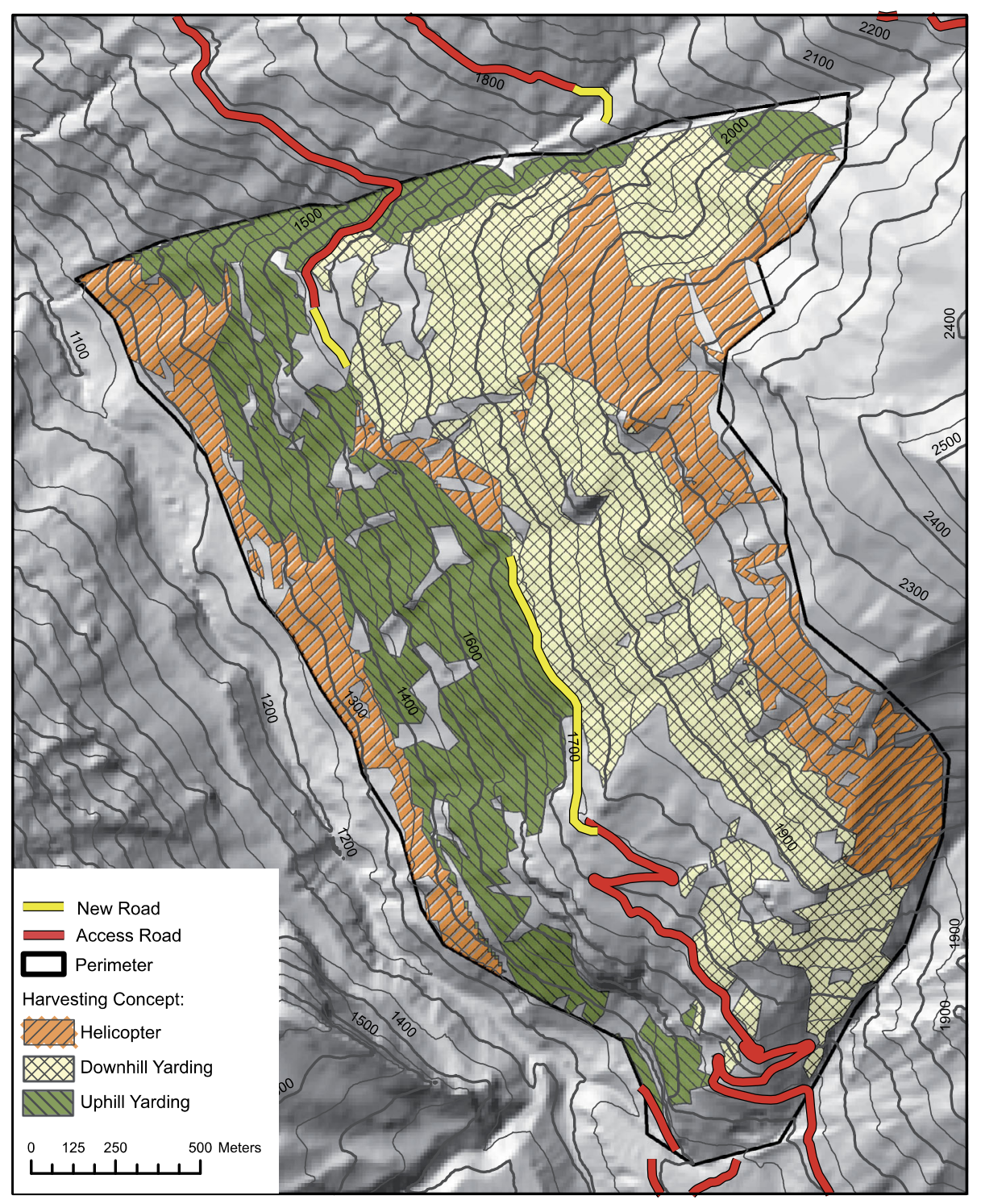

Fig. 7 Optimal road-layout and harvesting concept for Problem I (best-obtained solution). The same solution was achieved with either MRHCL or heuristics. (C) 2011 swisstopo (JD100042, JA100120)

\section{Discussion \& conclusion}

The goals of our investigation were to (1) create an optimization model for identifying the best road network that would concurrently minimize costs for road construction and for onand off-road transportation; and (2) compare our results with those gained via the greedy heuristics planning approach, as outlined by Epstein et al. (2006). The latter represents stateof-the-art methodology. 


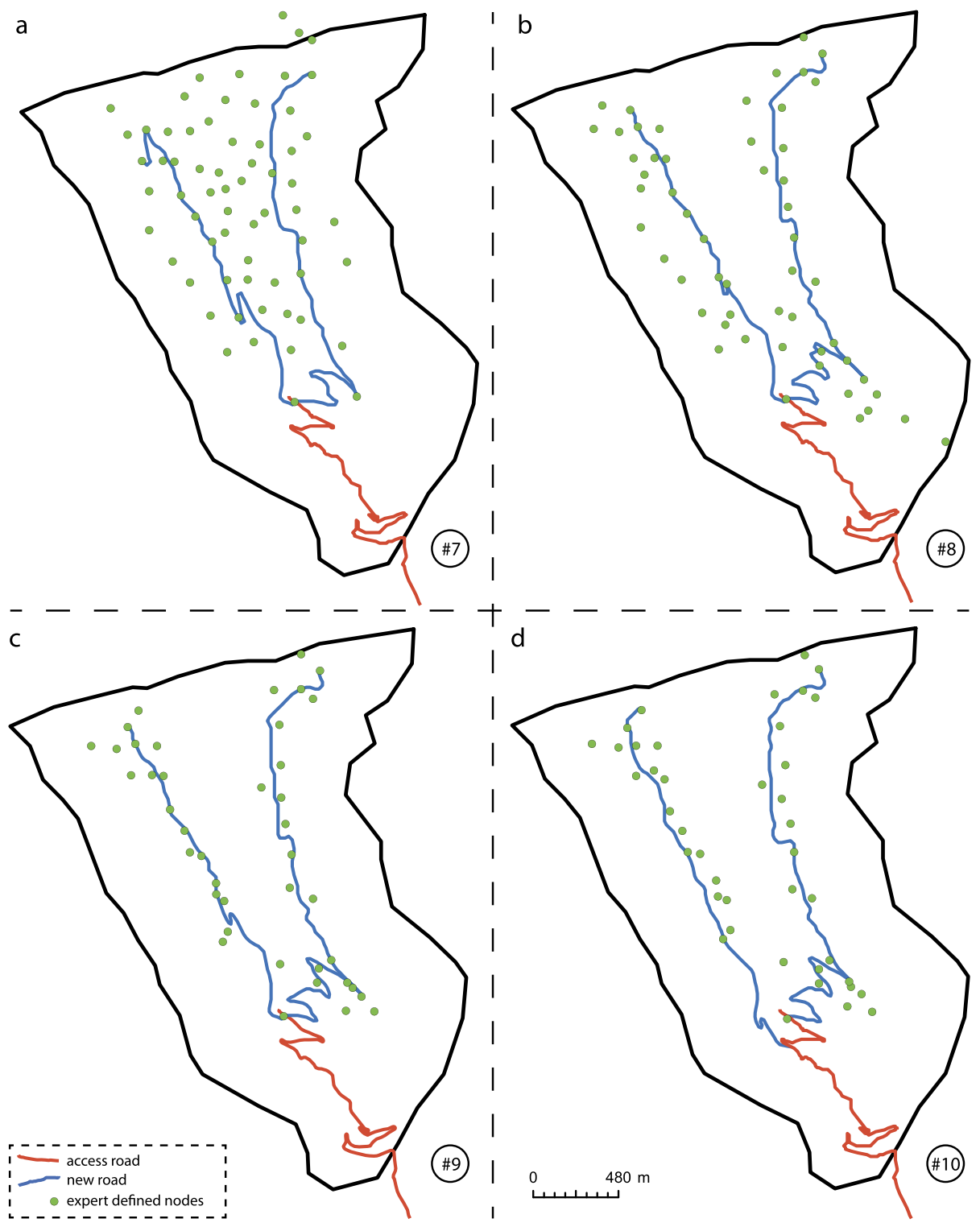

Fig. 8 Solution-finding process for Problem II. [a] MRHCL solved with the initial expert-defined nodes. [b] Nodes were re-set around the road branches obtained from the solution in [a] and the problem was re-solved. [c] Nodes were re-set around the road branches obtained from the solution in [b] and the problem was re-solved. [d] Node positions from [c] were slightly adjusted with an algorithm that detected areas of flat terrain and the problem was re-solved

We described this problem as facilitating the movement of harvested material-a system that required that each timber parcel flow into a cable road that first had to be connected to a road segment and eventually to an exit. To initiate the process, we manually distributed a set of nodes over the planning area at a density of about 20 to 25 per $\mathrm{km}^{2}$. Those nodes 

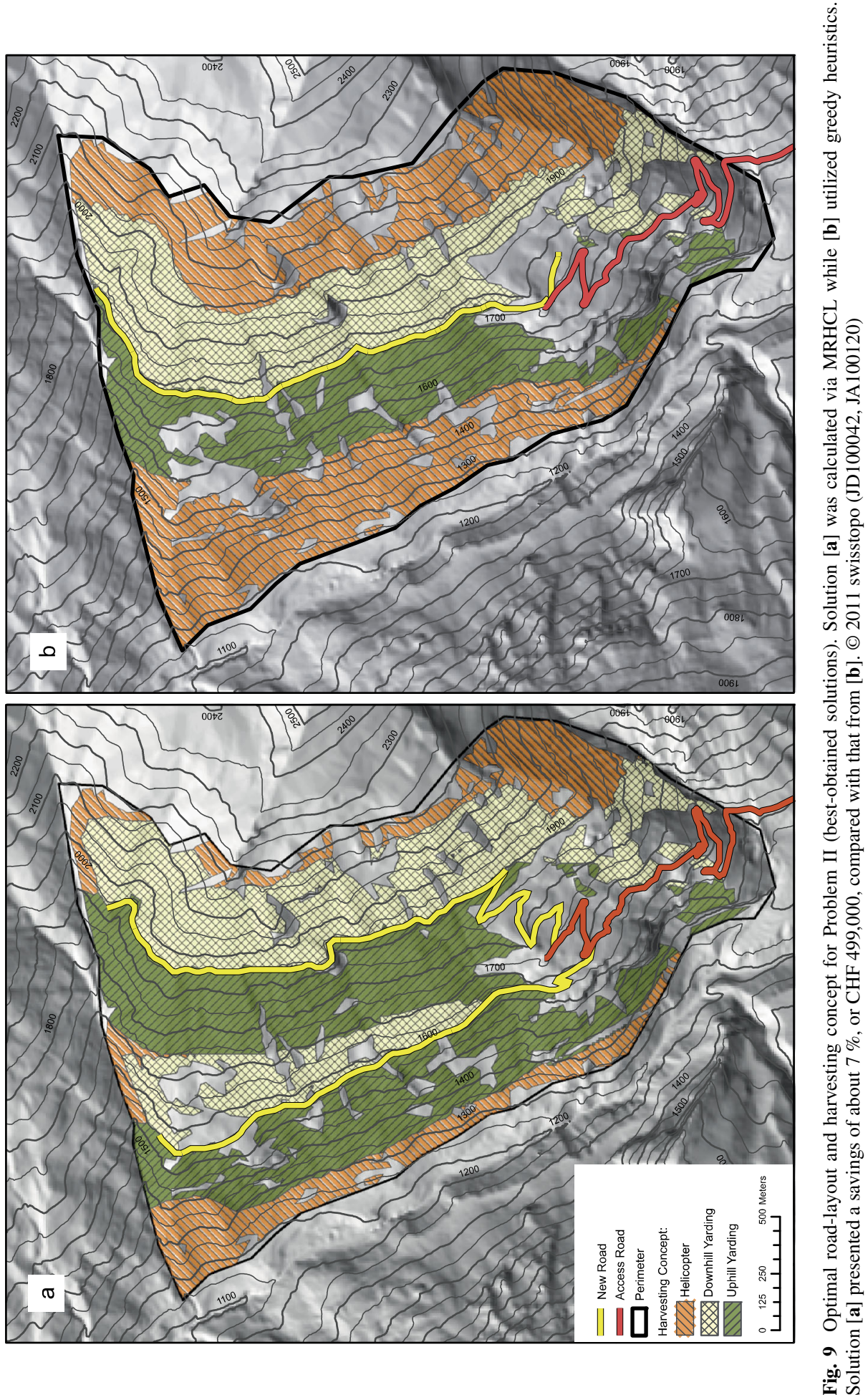
indicated potential terminals and junctions within our road network. Each node pair defined a possible segment while simultaneously identifying possible landing sites for connecting cable roads to truck roads. Our model parameters included costs for NPV of construction and maintenance, as well as off-road transport, e.g., cable-extraction. We did not consider the expense of hauling logs along the harvest road network because they were relatively independent of layout. That assumption, although not restrictive within the context of the system under study, was very efficacious to model development and solutions.

Our empirical results showed the following. First, by excluding on-road transport costs as a variable and introducing a set-cover constraint formulation, we delineated a problem that was much smaller in size and easier to solve than with previous approaches. Second, we learned that the MILP model formulation could be solved to optimality for real-world project areas within a reasonable timeframe. Depending on our choice of parameters, this method required a computing time of between $4 \mathrm{~min}$ and $8 \mathrm{hrs}$ for a project area of $4.3 \mathrm{~km}^{2}$. Third, our MILP approach (referred to here as MRHCL) provided results equal to or better than those gained from greedy heuristics. While we found no difference between the two over a relatively simple project area, MRHCL outperformed heuristics by about $7 \%$ for a non-trivial road network containing two parallel branches. We judged that outcome to be reasonable. Fourth, manual re-setting and re-adjusting of the initial nodes offered the potential to improve the objective value of the solution.

Our approach contributes to the state of knowledge in several ways. Up to now, heuristics approaches have often been used to generate near-optimal solutions to complex timberaccess problems. By comparison, our main new contribution to the literature has been to solve optimally some challenging problems via the MILP approach, even though the area of application might be only small to medium in size. Furthermore, it is the first optimization approach to incorporate explicitly the design elements that are required when applying single- and group-selection harvesting regimes, while also considering the specific conditions of steep terrain one often encounters in the Alps, e.g., cable roads running parallel to each other, the need for long-term durability for forest roads, and spatial variability in road construction costs.

Our findings have implications for road network engineers, government agencies, and operations-research scientists. Practitioners can obtain much better solutions compared with those gained from current practices, which are generally still based solely on previous experience, anecdotal evidence, or personal observations. Furthermore, government agencies can now use models to identify the best policies for given sets of costs and silvicultural requirements. Locational scientists can also apply this efficient formulation to reduce the size of their problem considerably.

However, improvements are needed for this model. Our study demonstrated that, in the process of assigning the initial set of nodes, we were framing the fitness of the solution as well. Further research is required for designing an algorithm that automatically generates an initial set of nodes, thereby leading to the best possible solution. Although we did not explore the maximum feasible problem size that could be tackled by this approach, based upon the length of time needed to solve Problem II ( 4 min to $8 \mathrm{hrs}$ for a project of $4.3 \mathrm{~km}^{2}$ ), we think that the upper limit for achieving reasonable results is less than $10 \mathrm{~km}^{2}$.

Because our test area was not located in an ecologically sensitive zone, we had to optimize for only a single objective: minimum cost. However, other planners might also have to minimize environmental impacts, such as for capercaillie habitat or marshland ecotopes (Stückelberger et al. 2006b). In Stückelberger's case, the environmental impact depended upon habitat quality and the length of road crossing the habitat. There, each segment could be assessed by the metric proposed by Stückelberger et al. (2006b). Afterward, one could 
introduce an environmental impact objective function such as stated below in Eq. (20). Here, $p_{r}$ would have represented the environmental impact of road segment $r$.

$$
\operatorname{Min} \sum_{r} p_{r} y_{r}^{R S}
$$

The relative weight of the different objectives (cost vs. environmental impact) would depend upon the preferences of the awarding authorities.

We assumed a given amount of timber was to be transported from each parcel and that each parcel had to be harvested. This was logical because of various silvicultural requirements, i.e., the forest must also provide protection against natural hazards; keeping it sustainable would require harvesting a certain volume of wood even if that operation were not economical. Therefore, we did not explicitly consider any parcel benefits or limitations on harvesting resources. However, our approach could also be used to maximize economic benefits and, therewith, detect those parcels for which harvesting would be economically feasible. While testing our scenarios, we also analyzed how our model could be used in alternative cases such as "helicopter logging". The expense incurred with that system would serve as an upper marginal cost for harvesting a unit via cable-yarding (including the cost of associated road access). For example, if the selling price were $80 \mathrm{CHF} / \mathrm{m}^{3}$ and benefits had to be maximized, then the cost of helicopter harvesting would be set at $80 \mathrm{CHF} / \mathrm{m}^{3}$. Hence, the timber parcels proposed for such an operation would prove uneconomical and should not be harvested whereas those proposed for cable-logging would be deemed feasible. Although we omitted other economics requirements, e.g., limits on total road costs, they could be easily incorporated into future evaluations by adding extra constraints.

Our approach was designed for implementations with steep terrain and group- or selection-cut systems. However, we predict that it would perform well for other silvicultural regimes, such as clear-cutting. Nevertheless, those harvesting scenarios must still be tested.

\section{References}

Anderson, A. E., \& Nelson, J. (2004). Projecting vector-based road networks with a shortest path algorithm. Canadian Journal of Forest Research, 34(7), 1444-1457.

Balakrishnan, A., Magnanti, T. L., \& Wong, R. T. (1989). A dual-ascent procedure for large-scale uncapacitated network design. Operations Research, 37(5), 716-740.

Bellmann, R. (1958). On a routing problem. Quarterly of Applied Mathematics, 16, 87-90.

Chung, W., Sessions, J., \& Heinimann, H. R. (2004). An application of a heuristic network algorithm to cable logging layout design. International Journal of Forest Engineering, 15(1), 11-24.

Chung, W., Stückelberger, J., Aruga, K., \& Cundy, T. (2008). Forest road network design using a trade-off analysis between skidding and road construction costs. Canadian Journal of Forest Research, 38(3), 439-448.

Church, R. L. (2008). BEAMR: an exact and approximate model for the p-median problem. Computers \& Operations Research, 35, 417-426.

Church, R. L., \& Cova, T. J. (2000). Mapping evacuation risk on transportation networks using a spatial optimization model. Transportation Research. Part C, Emerging Technologies, 8(1-6), 321-336. doi:10.1016/s0968-090x(00)00019-x.

Church, R. L., Gerrard, R., Hollander, A., \& Stoms, D. (2000). Understanding the tradeoffs between site quality and species presence in reserve site selection. Forest Science, 46(2), 157-167.

Clark, M., Meller, D., \& McDonald, P. (2000). A three-stage heuristic for harvest scheduling with access road network development. Forest Science, 46(2), 204-218.

Current, J. R., ReVelle, C. S., \& Cohon, J. L. (1985). The maximum covering/shortest path problem: a multiobjective network design and routing formulation. European Journal of Operational Research, 21(2), 189-199. 
Dean, D. J. (1997). Finding optimal routes for networks of harvest site access roads using GIS-based techniques. Canadian Journal of Forest Research, 27, 11-22.

Diaz, L. A., Ferland, J. A., Ribeiro, C. C., Vera, J. R., \& Weintraub, A. (2007). A tabu search approach for solving a difficult forest harvesting machine location problem. European Journal of Operational Research, 179(3), 788-805.

Dykstra, D. P., \& Riggs, J. L. (1977). An application of facilities location theory to the design of forest harvesting areas. IIE Transactions, 9(3), 270-277. doi:10.1080/05695557708975155.

Epstein, R., Morales, R., Séron, J., \& Weintraub, A. (1999). Use of OR systems in the Chilean forest industries. Interfaces, 29(1), 7-29.

Epstein, R., Weintraub, A., Sapunar, P., Nieto, E., Sessions, J. B., \& Sessions, J. (2006). A combinatorial heuristic approach for solving real-size machinery location and road design problems in forestry planning. Operations Research, 54(6), 1017-1027.

Heinimann, H. R. (1998). A computer model to differentiate skidder and cable-yarder based road network concepts on steep slopes. Journal of Forest Research (Japan), 3(1), 1-9.

Heinimann, H. R., \& Caminada, L. (1996). Helicopter logging in Switzerland, analysis of selective logging operations. In 9th pacific northwest skyline symposium, 40-45. FERIC special report SR-114, Vancouver, BC, Canada (p. 167).

Kirby, M. (1973). An example of optimal planning of forest roads and projects. In J. E. O’Leary (Ed.), Planning and decisionmaking as applied to forest harvesting, Forest Research Laboratory, School of Forestry, Oregon State University, Corvallis OR, USA (pp. 75-83).

Liu, K., \& Sessions, J. (1993). Preliminary planning of road systems using digital terrain models. Journal of Forest Engineering, 4(2), 6.

Mandt, C. I. (1973). Network analyses in transportation planning. In J. E. O’Leary (Ed.), Planning and decisionmaking as applied to forest harvesting, Forest Research Laboratory, School of Forestry, Oregon State University, Corvallis OR, USA (pp. 95-101).

Matisziw, T. C., Murray, A. T., \& Kim, C. (2006). Strategic route extension in transit networks. European Journal of Operational Research, 171, 661-673.

Matthews, D., \& Donald, M. (1942). Cost control in the logging industry. New York: McGraw-Hill. 374 pp.

Miller, C. E., Tucker, A. W., \& Zemlin, R. A. (1960). Integer programming formulation of traveling salesman problems. Journal of the Association for Computing Machinery, 7(4), 326-329. doi:10.1145/ 321043.321046 .

Murray, A. T. (1998). Route planning for harvest site access. Canadian Journal of Forest Research, 28(7), 1084-1087. doi:10.1139/x98-122.

Murray, A. T., \& Church, R. L. (1995). Heuristic solution approaches to operational forest planning problems. OR Spektrum, 17(2), 193-203. doi:10.1007/bf01719265.

O’Sullivan, D., \& Unwin, D. (2002). Geographic information analysis. New York: Wiley. 436 pp.

Park, C. S., \& Sharp-Bette, G. P. (1990). Advanced engineering economics. New York: Wiley. 470 pp.

Pestal, E. (1961). Seilbahnen und Seilkräne für Holz- und Materialtransporte. Wien und München: Georg Fromme \& Co.

Richards, W., \& Gunn, A. (2000). A model and tabu search method to optimize stand harvest and road construction schedules. Forest Science, 46(2), 188-203.

Rosing, K. E., \& ReVelle, C. S. (1997). Heuristic concentration: two stage solution construction. European Journal of Operational Research, 97, 75-86.

Stampfer, K., Limbeck-Lilienau, B., Kanzian, C., \& Viertler, K. (2003). In F. K. F. P. Papier (Ed.), Baumverfahren im Seilgelände, Verfahrensbeispiele, Wanderfalke mit Prozessor Woody 50, Syncrofalke mit Prozessor Wolf $50 \mathrm{~B}$. Wien: Institut für Alpine Naturgefahren und Forstliches Ingenieurwesen, Universität für Bodenkultur Wien.

Stampfer, K., Visser, R., \& Kanzian, C. (2006). Cable corridor installation times for European yarders. International Journal of Forest Engineering, 17(2), 71-77.

Stückelberger, J. A., Heinimann, H. R., \& Burlet, E. C. (2006a). Modeling spatial variability in the life-cycle costs of low-volume forest roads. European Journal of Forest Research, 125(4), 377-390.

Stückelberger, J. A., Heinimann, H. R., Chung, W., \& Ulber, M. (2006b). Automatic road-network planning for multiple objectives. In W. Chung \& H.-S. Han (Eds.), Council on forest engineering conference, Coeur d'Alene, ID, USA (pp. 233-248).

Stückelberger, J. A., Heinimann, H. R., \& Chung, W. (2007). Improved road network design models with the consideration of various link patterns and road design elements. Canadian Journal of Forest Research, 37(11), 2281-2298.

Twito, R. H., Reutebuch, S. E., Stephen, E., McGaughey, R. J., \& Mann, C. N. (1987). Preliminary logging analysis system PLANS. Overview (General Technical Report PNW-GTR-199). U.S. Department of Agriculture Forest Service, Pacific Northwest Research Station, Portland, OR, USA (p. 24). 